\title{
Efeito do número da passagem e do gênero das células doadoras de núcleo no desenvolvimento de bovinos produzidos por transferência nuclear
}

\author{
Giovana Krempel Fonseca Merighe ${ }^{1}$, Moysés dos Santos Miranda ${ }^{1}$, Tiago Henrique Câmara \\ de Bem $^{1}$, Yeda Fumie Watanabe ${ }^{2}$, Flávio Vieira Meirelles ${ }^{1}$ \\ ${ }^{1}$ Faculdade de Zootecnia e Engenharia de Alimentos da Universidade de São Paulo (FZEA/USP), Pirassununga, SP. \\ 2 Vitrogen-Pesquisa e Desenvolvimento em Biotecnologia da Reprodução S/C Ltda., Cravinhos, SP.
}

\begin{abstract}
RESUMO - Objetivou-se com este trabalho avaliar o efeito do número da passagem e do sexo das células doadoras de núcleo no desenvolvimento embrionário e fetal após transferência nuclear. Para isso, oócitos bovinos foram maturados, enucleados e reconstruídos com células somáticas de animal adulto. Após a fusão e ativação química, os zigotos reconstituídos foram cultivados em Charles Rosenkranz 2 (CR2) com monocamada de células da granulosa a $38,8^{\circ} \mathrm{C}$ em atmosfera umidificada a $5 \%$ de $\mathrm{CO}_{2}$ em ar, durante sete dias, e transferidos para receptoras sincronizadas. As taxas de clivagem e desenvolvimento a blastocisto de embriões reconstruídos com células cultivadas por tempo maior foram inferiores às obtidas com os demais tempos de cultivo. Além disso, os blastocistos produzidos não resultaram no desenvolvimento de uma gestação a termo. Embora a taxa de clivagem em embriões fêmeas tenha sido maior, o número de embriões que atingiram o estádio de blastocisto foi maior nos embriões machos. No período gestacional, fêmeas apresentaram maior taxa de aborto entre 90 e 120 dias de gestação. Esses resultados indicam que células doadoras de núcleos cultivados por longos períodos dificultam a produção de blastocistos e aumentam as chances de perdas durante a gestação. Embriões clonados machos têm maior competência para se desenvolver a blastocisto e resultam em menor taxa de perda gestacional.
\end{abstract}

Palavras-chave: bovino, fibroblastos, passagem celular, sexo, transferência nuclear

\section{Effect of culture time and gender of nuclei donor cells on bovine development produced by nuclear transfer}

\begin{abstract}
The objective of this study was to evaluate the effects of culture time and sex of nuclei donor cells on embryo and fetal development after nuclear transfer. Thus, bovine oocytes were matured, enucleated and reconstructed with somatic cells from an adult animal. After fusion and chemical activation, the reconstituted zygotes were cultured in Charles Rosenkranz 2 (CR2) on a granular monolayer cell at $38.8^{\circ} \mathrm{C}$ in a humidified atmosphere $5 \% \mathrm{CO}_{2}$ in air for seven days, and transferred to synchronized receptors. Cleavage rates and development to blastocyst of embryo reconstructed with cells cultured for a longer time were lower than rates obtained with other culture times. Moreover, these produced blastocysts did not result in the development of full term pregnancy. Although cleavage rates were higher in female embryos, the number of embryos that reached blastocyst stage was higher in male embryos. During gestation period, females showed higher abortion rates from 90 to 120 days of gestation. These results indicate that cells donnors of nuclei cultured for long periods make the production of blastocysts difficult and increase the chances of losses during pregnancy. Cloned male embryos are more succesful in becoming blastocysts and result in lower gestational loss rate.
\end{abstract}

Key Words: bovine, cell passage, fibroblast, nuclear transfer, sex

\section{Introdução}

Após os primeiros relatos de nascimentos de bovinos produzidos por transferência nuclear, vários estudos têm sido realizados para esclarecer as falhas desta biotecnologia e aprimorar sua eficiência (Prather et al., 1987).

Entre as etapas envolvidas, o período de cultivo das células doadoras de núcleo pode desestabilizar os eventos biológicos subsequentes ao processo, prejudicando e até interrompendo o desenvolvimento embrionário (Hamilton et al., 2001). As consequências de um período longo de cultivo in vitro se resumem em instabilidade cromossômica e encurtamento do telômero, que favorecem a perda da função de genes importantes para o desenvolvimento (Allsopp et al., 1992; Benn, 1976; Cibelli et al., 1998). Para reduzir esse efeito, muitos pesquisadores utilizaram células 
somáticas recém-colhidas ou cultivadas in vitro por períodos curtos (Kubota et al., 2000).

Além do período de cultivo, as células doadoras de núcleo parecem alterar o desenvolvimento embrionário quando se alterna o gênero utilizado no procedimento de clonagem, ou seja, o sexo do embrião pode ser determinante na taxa de blastocisto e na manutenção da gestação (Lê Bourhis et al., 1998).

A predominância de embriões machos ao final do desenvolvimento pré-implantação é rotineiramente observada em embriões produzidos por fecundação in vitro. Essa diferença está relacionado à capacidade desses embriões em suportar o estresse durante os primeiros estádios do desenvolvimento (Avery et al., 1989, 1991; Carvalho et al., 1996; Gutiérrez-Adán et al., 2001).

Em estudos com transferência de embriões de ambos os sexos, foi observado, aos 90 dias de gestação, maior número de fetos machos que de fêmeas. Esses embriões, durante o período de cultivo, foram expostos à variação de temperatura e à criopreservação, comprovando maior limitação pelos embriões do sexo feminino (King et al., 1992).

O desequilíbrio entre os gêneros pode ser atribuído à quantidade desproporcional de transcritos ligados ao cromossomo X em fêmeas (Shimizu et al., 1981), uma vez que o processo de inativação de um dos cromossomos $\mathrm{X}$ deveria resultar numa equivalência funcional com os machos, porém falhas neste processo acarretam perdas embrionárias (De La Fuente et al., 1999).

Os objetivos neste trabalho foram determinar a competência das células doadoras de núcleo após cultivo por período curto, intermediário e prolongado e avaliar o efeito do sexo no desenvolvimento in vitro e gestacional de embriões bovinos submetidos à transferência nuclear.

\section{Material e Métodos}

Os produtos químicos e os meios de cultivo foram adquiridos da Companhia de Produtos Químicos Sigma, St. Louis, MO, USA, exceto quando mencionado no texto.

Para a maturação dos oócitos, ovários de vacas zebus ou mestiças foram obtidos em abatedouro, transportados em solução salina $(0,9 \%)$ a $35^{\circ} \mathrm{C}$ e encaminhados até o laboratório. Os complexos cumulus-oócitos foram imediatamente aspirados de folículos de 2 a $8 \mathrm{~mm}$ utilizando uma seringa de $10 \mathrm{~mL}$ acoplada a uma agulha de $18 \mathrm{G}$. Foram selecionados para os experimentos somente os oócitos de qualidade I, com cumulus compacto completo e citoplasma límpido e de aspecto homogêneo (finas granulações). Os oócitos foram, em seguida, maturados em TCM199 com sais de Earle, glutamina e bicarbonato de sódio (Gibco
Lab., Grand Island, NY, USA) suplementado com $10 \%$ de soro fetal bovino (SFB), piruvato $(22 \mu \mathrm{g} / \mathrm{mL})$, gentamicina $(50 \mu \mathrm{g} / \mathrm{mL}), 0,5 \mu \mathrm{gdeFSH} / \mathrm{mL}$ (Folltropin ${ }^{\mathrm{TM}}$ ), $50 \mu \mathrm{g}$ dehCG $/ \mathrm{mL}$ (Vetecor ${ }^{\mathrm{TM}}$ ) e $1 \mu \mathrm{g}$ de estradiol $/ \mathrm{mL}$, em microgotas de $100 \mu \mathrm{L}$ de meio de maturação, cobertas com óleo mineral (30 oócitos/gota). A incubação foi realizada em temperatura de $38,8^{\circ} \mathrm{C}$ e atmosfera umidificada de $5 \% \mathrm{CO}_{2}$ em ar, durante 18 horas.

Após o período de maturação, os oócitos foram transferidos para uma solução-tampão-fosfato (PBS) suplementada com hialuronidase $(2 \mathrm{mg} / \mathrm{mL})$ e BSA $(4 \mathrm{mg} / \mathrm{mL})$ para remoção das células do cumulus por meio de sucessivas pipetagens e, então, foram selecionados com base na presença do primeiro corpúsculo polar. Em seguida, foram mantidos em meio CR2 (Watanabe et al., 1999) com citocalasina B $(10 \mu \mathrm{g} / \mathrm{mL})$ e corante Hoechst $33342(10 \mu \mathrm{g} / \mathrm{mL})$ durante 20 minutos. Os oócitos foram, então, enucleados em PBS com $10 \%$ de SFB e $10 \mu \mathrm{g} / \mathrm{mL}$ de citocalasina B, removendo uma pequena porção do citoplasma próxima à região do primeiro corpúsculo polar. Esta porção aspirada foi exposta a luz ultravioleta para confirmação da enucleação. Cada oócito foi, posteriormente, reconstruído com uma célula somática de um animal adulto no estádio G1/G0 do ciclo celular, inserindo a célula no espaço perivitelino.

Após 24 a 26 horas de maturação, os conjuntos oócitoscélulas somáticas foram transferidos para uma câmara de fusão e fundidos em solução contendo $0,3 \mathrm{M}$ de manitol, $0,1 \mathrm{mM} \mathrm{MgSO}_{4}, 0,5 \mathrm{mM}$ Hepes e $0,05 \%$ BSA. Os embriões reconstruídos foram alinhados manualmente de maneira que a superfície de contato entre oócito e célula estava paralela aos eletrodos. As células foram expostas a dois pulsos elétricos de $2,25 \mathrm{kV} / \mathrm{cm}$ durante $65 \mu \mathrm{seg}$. Aproximadamente uma hora após a eletrofusão, os oócitos fundidos foram quimicamente ativados em $5,0 \mu \mathrm{M}$ de ionomicina em TCM tamponado com Hepes e suplementado com $1 \mathrm{mg} / \mathrm{mL}$ de BSA durante 5 minutos e, em seguida, cultivados em CR2 acrescido de 2,0 $\mathrm{mM}$ de 6-dimetilaminopurina (6DMAP) durante 3 horas, em temperatura de $38,8^{\circ} \mathrm{C}$ e atmosfera umidificada de $5 \%$ $\mathrm{CO}_{2}$ em ar.

Ao término do período de ativação, os oócitos foram cultivados em meio CR2 suplementado com $10 \%$ de SFB em co-cultivo com células da granulosa, em temperatura de $38,8^{\circ} \mathrm{C}$ e atmosfera umidificada de $5 \% \mathrm{CO}_{2}$ em ar, durante sete dias, quando foram transferidos individualmente para receptoras sincronizadas.

As linhagens de células somáticas utilizadas como doadoras de núcleo foram derivadas de biópsias da pele de animais adultos machos (3) e fêmeas (5) da raça Nelore. A biópsia foi retirada da prega da cauda do animal e 
transportada imediatamente para o laboratório em PBS em gelo. O tecido foi triturado em pequenos pedaços de aproximadamente $2 \mathrm{~mm}$, que foram lavados em PBS e fixados numa placa dePetride $35 \mathrm{~mm}$ de diâmetro. Ocultivo procedeu-se em meio de Eagle modificado por Dulbelcco (DMEM; Gibco) suplementado com $20 \%$ de SFB, piruvato $(22 \mu \mathrm{g} / \mathrm{mL})$, glutamina $(1 \mathrm{mM})$ e gentamicina $(50 \mu \mathrm{g} / \mathrm{mL})$. A incubação foi realizada em temperatura de $38,8^{\circ} \mathrm{C}$ e atmosfera umidificada de $5 \% \mathrm{CO}_{2}$ em ar, renovando-se o meio a cada três dias.

Após crescimento das primeiras células, o meio foi substituído por DMEM suplementado com $10 \%$ de SFB e processado até a terceira passagem, momento em que os fibroblastos estavam prontos para a transferência nuclear. Aproximadamente cinco dias antes da realização do experimento, o meio de cultivo foi substituído por DMEM suplementado com $0,5 \%$ de SFB (restrição de soro), buscando aumentar o número de células no estádio G1/G0.

Os tratamentos utilizados neste estudo basearam-se em características das células doadoras, ou seja, foram preparadas células em passagens iniciais ( $3^{\mathrm{a}}$ a $5^{\mathrm{a}}$ ), em passagens intermediárias (6 $6^{\mathrm{a}}$ a $8^{\mathrm{a}}$ ) e em passagens tardias (9 $\left.{ }^{\mathrm{a}} \mathrm{a} 12^{\mathrm{a}}\right)$, bem como, células do gênero masculino e feminino.

As taxas de desenvolvimento embrionário pré e pósimplantação dos embriões bovinos submetidos à transferência nuclear foram avaliadas utilizando a análise qui-quadrado $\left(\mathrm{c}^{2}\right)$. Diferenças no desenvolvimento entre os grupos foram transformadas a anti-log para aproximar a uma distribuição normal e avaliadas pelo teste de análise de variância e submetidas a comparação das médias pelo teste t de Student, pelo programa JMP, versão 2.4 SAS Institute (Cary, NC, EUA).

\section{Resultados e Discussão}

Para avaliar o efeito do número da passagem na competência de desenvolvimento a blastocisto, 5.629 oócitos foram submetidos ao procedimento de transferência nuclear. Desses, 3.076 (55\%) zigotos foram efetivamente reconstruídos (fundidos), 2.349 (42\%) embriões alcançaram o estádio de duas células (clivaram), 934 (17\%) desenvolveram até o estádio de oito células e 438 (8\%) formaram um blastocisto.

Células doadoras de passagens iniciais ( $3^{\mathrm{a}}$ a $5^{\mathrm{a}}$ ) e intermediárias ( $6^{\mathrm{a}}$ a $8^{\mathrm{a}}$ ) apresentaram taxas de clivagem e desenvolvimento de até oito células, resultados significativamente melhores que os obtidos com as células de passagens tardias (cultivadas mais tempo) (9 $9^{\mathrm{a}}$ a $12^{\mathrm{a}}$; $\mathrm{p}<0,05$; Figura 1). Além disso, zigotos reconstituídos com células oriundas de passagens iniciais apresentaram maior competência para o desenvolvimento a blastocisto em comparação àqueles reconstituídos com passagens intermediárias e tardias. Da mesma maneira, maior número de embriões produzidos com células em passagens intermediárias desenvolveu até o estádio de blastocisto em comparação àqueles produzidos com células de passagens $\operatorname{tardias}(\mathrm{p}<0,05)$.

$\mathrm{Na}$ avaliação do desenvolvimento gestacional, 277 embriões no $7 \underline{0}$ dia de cultivo in vitro foram transferidos para receptoras, porém em apenas $75(30 \%)$ delas foi confirmada prenhez aos 30 dias, resultando em 21 (8\%) gestações a termo (com sucesso). Dessas gestações, 11 (4\%) animais clonados sobreviveram após o nascimento.

Embora o grupo de embriões produzidos com células obtidas de passagens tardias tenha resultado em taxas de prenhez aos 30 dias semelhantes, as gestações obtidas com esse grupo de embriões não foram a termo (Figura 2).

Embriões reconstruídos com células em passagens iniciais não diferiram quanto às taxas de gestação a termo em comparação aos obtidos com as células intermediárias (34 e 25\%, respectivamente, $\mathrm{p}>0,05$ ). As taxas de sobrevivência após o nascimento foram semelhantes entre os grupos (50 e 57\%, respectivamente; $p>0,05$ ).

Durante o período de gestação, as receptoras apresentaram perdas gestacionais a partir das primeiras semanas de gestação até o nascimento dos bezerros. Não houve diferença significativa entre os intervalos das passagens das células doadoras, porém a gestação de embriões clones apresentou três fases principais de perda gestacional: no período de implantação, ou seja, nos primeiros dias de desenvolvimento, evidenciado pela baixa taxa de prenhez aos 30 dias; no período que variou entre 30 e 60 dias; e também durante a organogênese, entre 90 e 150 dias de gestação (Figura 3).

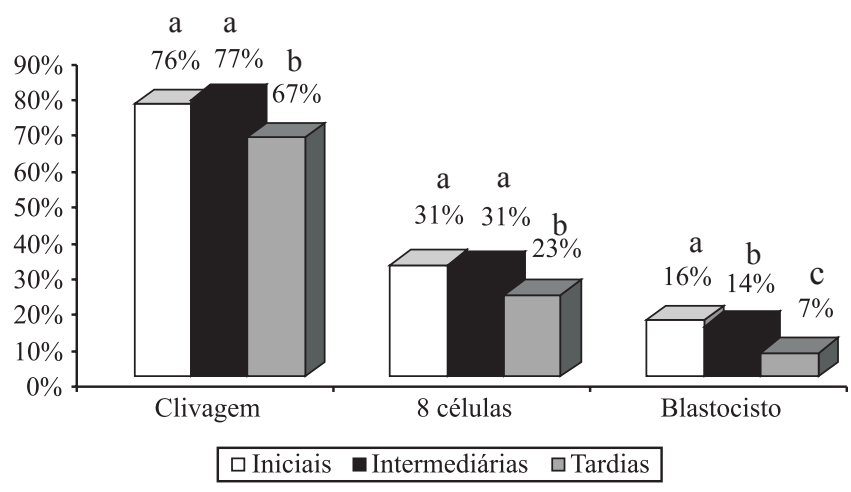

Letras distintas indicam diferenças $(\mathrm{p}<0,05)$ entre os grupos.

Figura 1 - Taxas de desenvolvimento de embriões bovinos reconstruídos com células doadoras cultivadas em diferentes passagens. 
Uma grande preocupação sobre a utilização de células oriundas de longas passagens no procedimento de transferência nuclear é o efeito de seu estado de senescência na eficiência da clonagem. Esse envelhecimento celular compromete a divisão celular e torna-se um fator limitante na biotecnologia animal (Jang et al., 2004).

Neste estudo os embriões reconstruídos com células oriundas de passagens tardias apresentaram menor taxa de desenvolvimento a blastocisto, assim como nenhuma gestação foi concluída, comprovando que tempos de cultivo prolongados das células doadoras de núcleo interferiram negativamente no desenvolvimento embrionário e fetal.

Apesar de não terem sido encontradas diferenças no desenvolvimento de embriões clones entre os três intervalos de passagem das células doadoras, Jang et al. (2004)

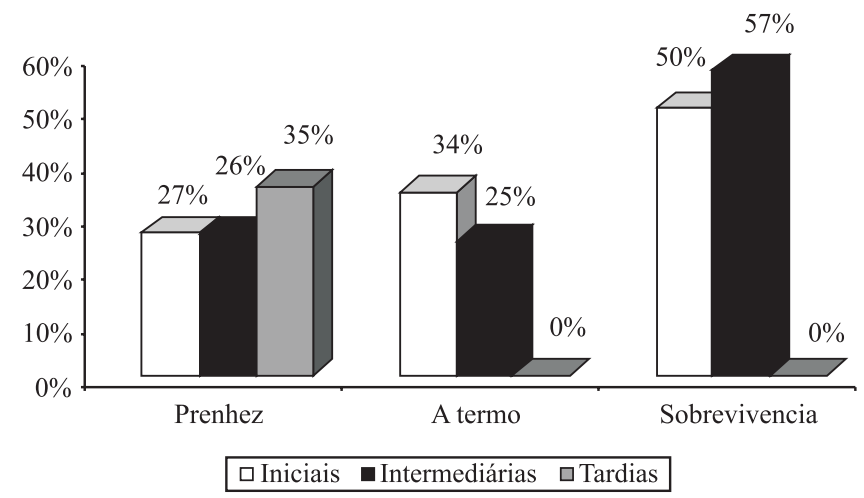

Figura 2 - Taxas de prenhez aos 30 dias, gestação a termo e sobrevivência após o nascimento de embriões submetidos a transferência nuclear com células somáticas em três intervalos de passagem. evidenciaram maior número de blastômeros em apoptose em embriões reconstruídos com células cultivadas por longos períodos. Assim, é possível que o uso dessas células diminua as taxas de prenhez e nascimento pela redução da viabilidade dos blastocistos produzidos.

Em pesquisas com células transfectadas, em que é necessário cultivo prolongado para a integração estável do gene nas células doadoras, vários pesquisadores observaram menor taxa de desenvolvimento embrionário após o procedimento de clonagem (Arat et al., 2001; Roh et al., 2000; Schnieke et al., 1997; Westhusin et al. 2001). Em contraste, Kubota et al. (2000) relataram que fibroblastos oriundos da pele de um animal adulto e cultivados por um período longo (acima da 15a passagem) apresentaram maiores taxas de desenvolvimento em comparação àqueles cultivados por período curto e resultaram em nascimentos com sucesso. Além disso, Bhuiyan et al. (2004) também não encontraram efeito dos intervalos das passagens das células doadoras transfectadas no desenvolvimento in vitro de embriões transgênicos $\left(3^{\mathrm{a}} \mathrm{a} 7 \underline{\mathrm{a}}=11 \% ; 8^{\mathrm{a}} \mathrm{a} 12^{\mathrm{a}}\right.$ passagens $=$ $12 \%$ de blastocistos).

Embora esses estudos não tenham revelado diferenças entre as passagens, a literatura evidencia que células oriundas de longas passagens desencadeiam alterações genéticas e epigenéticas que se acumulam durante os vários ciclos de divisões celulares, resultando em falhas durante a gestação que levam ao aborto ou a problemas congênitos (Campbell et al., 1996; Rumpf, 2007).

Esses problemas foram detectados por Walker et al.(1996) e Young et al. (1998) quando analisaram a expressão de genes importantes para o desenvolvimento embrionário.

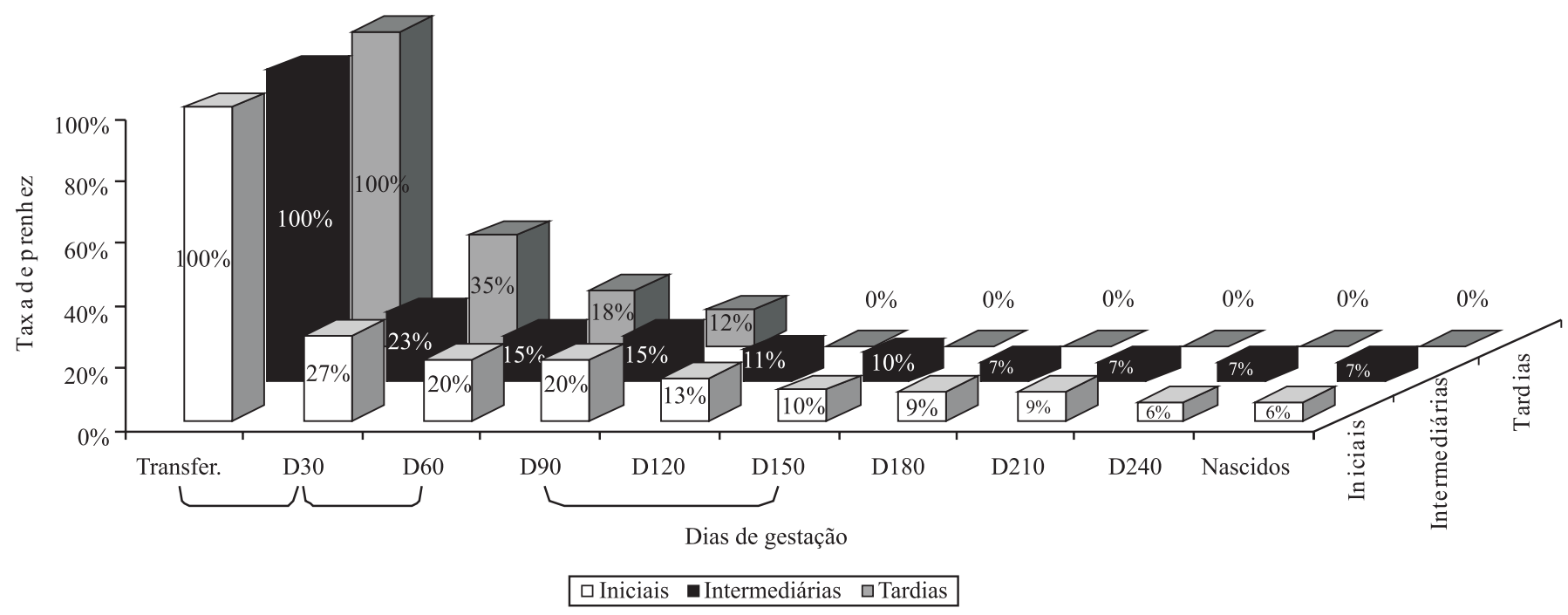

Os colchetes indicam os intervalos de maior perda gestacional.

Figura 3 - Evolução da gestação após a transferência de embriões bovinos produzidos por transferência nuclear de células somáticas em em três intervalos de passagem. 
Esses autores observaram que as alterações na regulação de genes imprinting foram consequência da utilização de células doadoras de núcleo cultivadas por longos períodos, inviabilizando o desenvolvimento embrionário e fetal. Outros pesquisadores demonstraram que, embora embriões oriundos de células em passagens iniciais e tardias tenham sido capazes de suportar o desenvolvimento in vitro após o procedimento de transferência nuclear, aqueles oriundos de tempos de cultivo prolongados apresentam taxas reduzidas de formação de blastocistos (Roh et al., 2000). Neste estudo, embriões reconstruídos com células somáticas cultivadas por curtas e intermediárias passagens foram equivalentemente competentes quanto às taxas de prenhez e gestação a temo, entretanto, aqueles produzidos com células em passagens tardias (9 $9^{\mathrm{a}}$ a $12^{\mathrm{a}}$ passagens) não resultaram em gestações com sucesso, portanto devem ser evitadas no procedimento de transferência nuclear.

Para avaliação do efeito do sexo dos fibroblastos no desenvolvimento de embriões produzidos por transferência nuclear, foi excluído das análises o grupo de embriões reconstruídos com células somáticas de passagens prolongadas como forma de evitar a influência dessa variável.

Durante o desenvolvimento pré-implantação (clivagem, formação de oito células e formação de blastocisto), o gênero da célula doadora de núcleo apresentou efeito significativo nos resultados obtidos. Embriões fêmeas apresentaram maior taxa de clivagem ( $78 \%$ vs $74 \%$; $<<0,05)$, porém menor taxa de formação de blastocisto, em comparação aos machos ( $14 \%$ vs $16 \%$; p $<0,05)$. Embriões machos e fêmeas não diferiram entre si quanto ao estádio de oito células (Figura 4).

Apesar da similaridade nas taxas de prenhez aos 30 dias entre indivíduos machos e fêmeas, os resultados sugerem tendência a maior competência de desenvolvimento a termo de machos em comparação a fêmeas $(40 \%$ vs $27 \%$, respectivamente; $p=0,13$; Figura 5). Da mesma maneira, bezerros nascidos a partir de embriões produzidos por transferência nuclear utilizando células masculinas doadoras de núcleos apresentaram tendência a maior taxa de sobrevivência em relação àqueles nascidos de células femininas ( $63 \%$ vs $46 \%$, respectivamente; $p=0,14$ ).

Como mencionado, as receptoras apresentaram perdas gestacionais a partir do momento em que o embrião foi transferido até o nascimento dos bezerros. Durante esse período, as diferenças entre os sexos foram significativas, uma vez que fêmeas apresentaram maior taxa de aborto entre 90 a 150 dias de gestação (Figura 6).

O desequilíbrio no desenvolvimento de embriões bovinos machos e fêmeas acontece rotineiramente nos laboratórios de produção in vitro, revelando número maior de embriões machos que se desenvolveram até o estádio de blastocisto (Gutiérrez-Adán et al., 1996; Lonergan et al., 1999).

Embora os fatores que influenciam esses desvios sejam desconhecidos, a maioria dos autores revela maior número de nascimento de bezerros, evidenciando que esse desvio também ocorre durante o período gestacional (GutiérrezAdán et al., 1996; Lonergan et al., 1999).

Os dados apresentados na literatura sobre embriões produzidos por fecundação in vitro foram confirmados neste trabalho, tendo em vista a diferença entre embriões machos e fêmeas produzidos por transferência nuclear. Além de maior taxa de desenvolvimento a blastocisto para embriões machos, ficou evidente também o sucesso das gestações de machos, sugerindo uma possível alteração no desenvolvimento de fêmeas.

Essa possível vantagem dos embriões do sexo masculino não foi observada por alguns pesquisadores, que, analisando os eventos de clivagem, estádio de compactação e formação de blastocisto, não identificaram desproporção entre os sexos (Carvalho et al., 1995; King et al., 1991; Holm et al., 1998). Avaliando o período gestacional, Lê Bourhis et al. (1998) também não encontraram diferenças nas taxas de prenhez aos 35 dias, aos 90 dias e de nascimento de embriões produzidos por transferência nuclear.

Apesar da controvérsia, a maioria dos relatos da literatura comprova esse desvio e sugere que o ponto crítico que distancia a produção de machos da produção de fêmeas ocorra entre os estádios de blastocisto inicial e demais fases de blastocisto (Carvalho et al., 1996). Esses autores encontraram maior produção de blastocistos machos expandidos e eclodidos no $7 \underline{0}$ dia de cultivo (68 e 100\%,

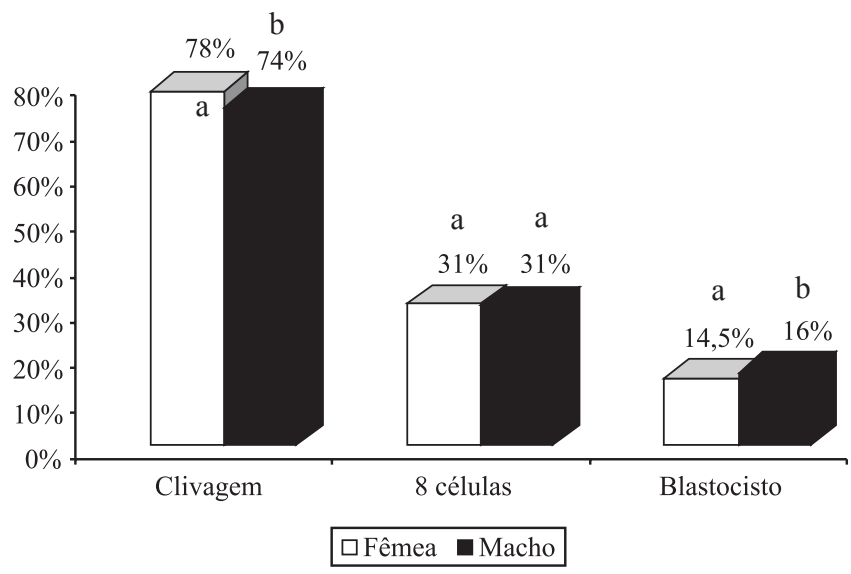

Letras distintas indicam diferenças $(\mathrm{p}<0,05)$ entre os grupos.

Figura 4 - Taxas de clivagem, formação de oito células e formação de blastocisto de embriões submetidos a transferência nuclear com células femininas e masculinas. 
respectivamente) em comparação ao estádio de mórula, no qual observaram menor proporção (24\%).

Por outro lado, outros autores observaram efeitos de distorção entre machos e fêmeas logo no $3^{0}$ dia após a inseminação, no estádio de oito células no bovino, que coincide com a primeira expressão do genoma embrionário, quando a capacidade de síntese de RNA é adquirida (Marquant-Le Guienne etal., 1992; Kopecny \& Niemann, 1993).

Apesar de pouco esclarecido, alguns pesquisadores acreditam que o desequilíbrio entre os gêneros seja consequência da composição do meio de cultivo, principalmente na concentração de glicose. O consumo de glicose por embriões bovinos aumenta acentuadamente em duas etapas importantes do desenvolvimento: o início da transcrição do genoma embrionário ( 8 a 16 células) e a compactação (Rieger et al., 1992).

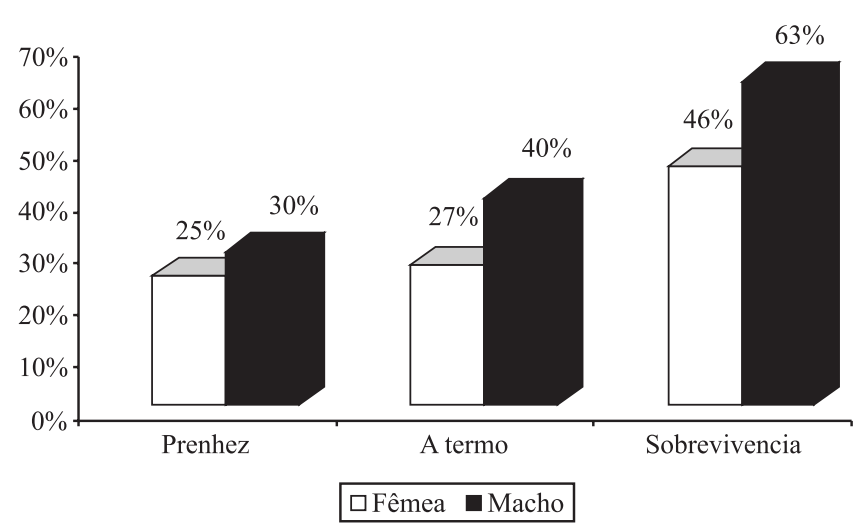

Figura 5 - Taxas de prenhez, gestação a termo e sobrevivência após o nascimento de embriões submetidos a transferência nuclear com células doadoras de núcleos femininas e masculinas.
Parte do metabolismo da glicose é realizada por enzimas ligadas ao cromossomo $\mathrm{X}$, que, por estarem descompensadas em fêmeas no início do desenvolvimento embrionário, podem acarretar letalidade embrionária (King et al., 2006). Por não ocorrer com os machos, essas enzimas aparecem em níveis normais, o que permite seu desenvolvimento em maior velocidade (Lequarre et al., 1997).

Thibier \& Nibart (1995), em pesquisa com embriões produzidos in vivo, não observaram diferença na relação 50:50 (54\% de nascimentos de embriões machos e $46 \%$ de fêmeas), confirmando que o desequilíbrio é um efeito do sistema de produção in vitro. A influência das condições de cultivo in vitro aparece também em outras espécies, pois estudos revelam uma perda preferencial de embriões de camundongos fêmeas em comparação a embriões machos (Gutierrez-Adán et al., 1993).

Durante o período gestacional, foram evidenciados pontos críticos que parecem ser característicos de gestação de clones, pois houve equivalência de perda gestacional para ambos os sexos no primeiro trimestre de gestação (entre 30 e 90 dias; Figura 6). A partir desse momento, houve maior perda na gestação de fêmeas que na gestação de machos $(\mathrm{p}<0,05)$. Embora a taxa de mortalidade após o nascimento de fêmeas tenha sido superior à de machos, os resultados não foram significativos (fêmeas 6/13; machos 5/8). Esse período de perda gestacional, caracterizado principalmente pelos dias 90 a 150 da gestação, coincide com a organogênese, assim, a maior taxa de aborto de fêmeas pode ser consequência de maiores alterações congênitas.

O efeito associado entre as condições de cultivo in vitro e o desequilíbrio nos níveis de enzimas metabolicamente importantes no início do desenvolvimento, devido

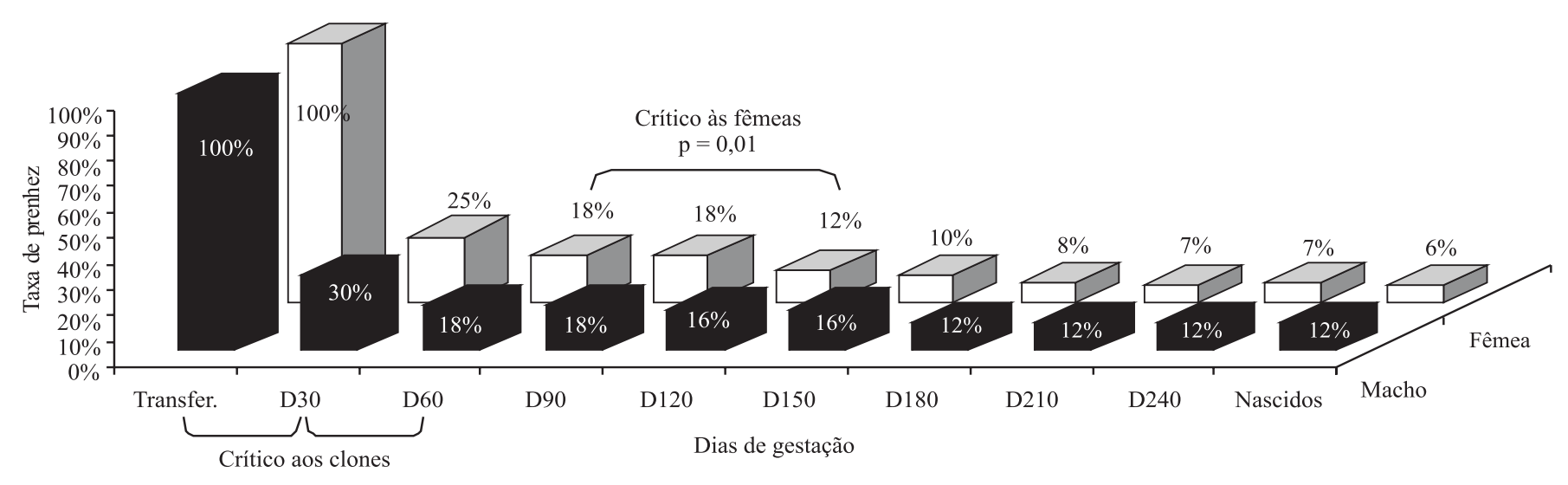

Os colchetes indicam o período crítico de perda gestacional.

Figura 6 - Evolução da gestação após a transferência de embriões bovinos machos e fêmeas produzidos por transferência nuclear de células somáticas. 
ao silenciamento de genes ligados ao cromossomo X, pode ser uma possível explicação para falhas no desenvolvimento de fêmeas.

\section{Conclusões}

Células doadoras de núcleos cultivadas por longas passagens prejudicam a produção de blastocistos e aumentam as chances de perdas durante a gestação em embriões produzidos por transferência nuclear de células somáticas. Além disso, células masculinas quando aplicadas na transferência nuclear resultam em maior taxa de desenvolvimento embrionário e menor taxa de perda gestacional no período entre 90 e 150 dias.

\section{Agradecimentos}

À Fundação de Amparo à Pesquisa do Estado de São Paulo (FAPESP) pelo apoio financeiro, à CLONEST ${ }^{\circledR}$ pela parceria e à FZEA/USP pela viabilização da pesquisa.

\section{Referências}

ALLSOPP, R.C.; VAZIRI, H.; PATTERSON, C. et al. Telomere length predicts replicative capacity of human fibroblasts. Proceedings of the National Academy of Sciences of the United States of America, v.89, p.10114-10118, 1992.

ARAT, S.; RZUCIDLO, S.J.; GIBBONS, J. et al. Produciton of transgenic bovine embryos by transfer of transfected granulosa cells into enucleated oocytes. Molecular Reproduction and Development, v.60, p.20-26, 2001.

AVERY, B.; BAK, A.; SCHMIDT, M. Differential cleavage rates and sex determination in bovine embryos. Theriogenology, v.32, p.139-147, 1989.

AVERY, B.; MADISON, V.; GREVE, T. Sex and development in bovine in-vitro fertilized embryos. Theriogenology, v.35, p.953-963, 1991.

BENN, P.A. Specific chromosome aberrations in senescent fibroblast cell lines derived from human embryos. American Journal of Human Genetics, v.28, p.465-473, 1976.

BHUIYAN, M.M.U.; CHO, J.; JANG, G. et al. Effect of transfection and passage number of ear fibroblasts on in vitro development of bovine transgenic nuclear transfer embryos. The Journal of Veterinary Medical Science, v.66, n.3, p.257-261, 2004.

CAMPBELL, K.H.S.; LOI, P.; OTAEGUI, P.J. et al. Cell cycle co-ordination in embryo cloning by nuclear transfer. Reviews of Reproduction, v.1, p.40-46, 1996.

CARVALHO, R.V.; DEL CAMPO, M.R.; PLANTE, Y. et al. Effects of stage of development on sex ratio and survival after freezing of day 7 bovine IVF embryos. Theriogenology, v. 43, p. $183,1995$.

CARVALHO, R.V.; DEL CAMPO, M.R.; PALASZ, A.T. et al. Survival rates and sex ratio of bovine IVF embryos frozen at different developmental stages on day 7. Theriogenology, v.45, p.489-498, 1996.

CiBelli, J.B.; STICE, S.L.; GOLUEKe, P.J. et al. Cloned transgenic calves produced from nonquiescent fetal fibroblasts. Science, v.280, p.1256-1258, 1998.
DE LA FUENTE, R.; HAHNEL, A.; BASRUR, P.K. et al. X Inactivespecific transcript (Xist) expression and $X$ chromosome inactivation in the preattachment bovine embryo. Biology of Reproduction, v.60, p.769-775, 1999.

GUTIERREZ-ADÁN, A.; PINTADO, B.; FUENTES, S. et al. Influence of micromanipulation and in vitro culture in the sex dependent loss of embryos. In: SCIENTIFIC MEETING OF EUROPE ASSOCIATION AETE, 9., 1993, Lyon. Proceedings... Lyon: 1993. p.206.

GUTIÉRREZ-ADÁN, A.; BEHBOODI, E.; ANDERSON, G.B. et al. Relationship between stage of development and sex of bovine IVM-IVF embryos cultured in vitro versus in the sheep oviduct. Theriogenology, v.46, p.515-525, 1996.

GUTIÉRREZ-ADÁN, A.; LONERGAN, P.; RIZOS, D. et al. Effect of the in vitro culture system on the kinetics of blastocyst development and sex ratio of bovine embryos. Theriogenology, v.55, p.1117-1126, 2001.

HAMILTON, M.L.; VAN REMMEN, H.; DRAKE, J.A. et al. Does oxidative damage to DNA increases with age? Proceedings of the National Academy of Sciences of the United States of America, v.98, p.10469-10474, 2001.

HOLM, P.; SHUKRI, N.N.; VAJTA, G. et al. Developmental kinetics of the first cell cycles of bovine in vitro produced embryos in relation to their in vitro viability and sex. Theriogenology, v.50, p.1285-1299, 1998.

JANG, G.; PARK, E.S.; CHO, H.K. et al. Preimplantation embryo development and incidence of blastomere apoptosis in bovine somatic cell nuclear transfer embryos reconstructed with long-term cultured cells. Theriogenology, v.62, p.512-521, 2004.

KING, W.A.; YADAV, B.R.; XU, K.P. et al. The sex ratios of bovine embryos produced in vivo and in vitro. Theriogenology, v.36, p.779-788, 1991.

KING, W.A.; PICARD, L.; BOUSQUET, D. et al. Sex-dependent loss of bisected bovine morulae after culture and freezing. Journal of Reproduction and Fertility, v.96, p.453-459, 1992.

KING, W.A; COPPOLA, G.; ALEXANDER, B. et al. The impact of chromosomal alteration on embryo development. Theriogenology, v.65, p.166-177, 2006.

KOPECNY, V.; NIEMANN, H. Formation of nuclear microarchitecture in the preimplantation bovine embryo at the onset of transcription: implications for biotechnology. Theriogenology, v.39, p.109-119, 1993.

KUBOTA, C.; YAMAKUCHI, H.; TODOROKI, J. et al. Six cloned calves produced from adult fibroblast cells after long-term culture. Proceedings of the National Academy of Sciences of the United States of America, v.97, n.3, p.990-995, 2000.

LE BOURHIS, D.; CHESNE, P.; NIBART, M. et al. Nuclear transfer from sexed parent embryos in cattle: efficiency and birth of offspring. Journal of Reproduction and Fertility, v.113, p.343-348, 1998.

LEQUARRE, A.S.; GRISART, B.; MOREAU, B. et al. Glucose metabolism during bovine preimplantation development: analysis of gene expression in single oocytes and embryos. Molecular Reproduction and Development, v.48, p.216-226, 1997.

LONERGAN, P.; KHATIR, H.; PIUMI, F. et al. Effect of time interval from insemination to first cleavage on the developmental characteristics, sex ratio and pregnancy rate after transfer of bovine embryos. Journal of Reproduction and Fertility, v.117, p.159-167, 1999.

MARQUANT-LE GUIENNE, B.; NIBART, M.; GUYADER, C. et al. DNA probe sexing of young in vitro fertilized bovine embryos. Theriogenology, v.37, p.253, 1992.

PRATHER, R.S.; BARNES, F.L.; SIMS, M. et al. Nuclear transplantation in the bovine embryo: assessment of donor nuclei and recipient oocytes. Biology of Reproduction, v.37, p.859-866, 1987.

RIEGER, D. Relationship between energy metabolism and development of early mammalian embryos. Theriogenology, v.37, p.75-93, 1992. 
ROH, S.; SHIM, H.; HWANG, W.S. et al. In vitro development of green fluorescent protein (GFP) transgenic bovine embryos after nuclear transfer using different cell cycles and passages of fetal fibroblasts. Reproduction, Fertility and Development, v.12, p.1-6, 2000.

RUMPF, R. Avanços metodológicos na produção in vitro de embriões. Revista Brasileira de Zootecnia, v. 36, suplemento especial, p. 229-233, 2007.

SCHNIEKE, A.E.; KIND, A.J.; RITCHIE, W.A. et al. Human factor IX transgenic sheep produced by transfer of nuclei from transfected fetal fibroblasts. Science, v.278, p.2130-2133, 1997.

SHIMIZU, N.; SHIMIZU, Y.; KONDO, I. et al. The bovine genes for phosphoglycerate kinase, glucose-6-phosphate dehydrogenase, alpha-galactosidase and hypoxanthine phosphoribosyltransferase are linked to the $\mathrm{X}$ chromosome in cattle-mouse cell hybrids. Cytogenetics and Cell Genetics, v.29, n.1, p.26-31, 1981.
STATISTICAL ANALYSIS SYSTEM - SAS. User's guide. 8.ed. Cary: SAS Institute, 1991. 1028p.

THIBIER, M.; NIBART, M. The sexing of bovine embryos in the field. Theriogenology, v.43, p.71-80, 1995.

WALKER, S.K.; HARTWICH, K.M.; SEAMARK, R.F. The production of unusually large offspring following embryo manipulation: concepts and challenges. Theriogenology, v.45, p.111-120, 1996.

WATANABE, Y.F.; WATANABE, M.R.; GALERANI, M.A.V. et al. The influence of $\mathrm{B} 2$ and a modified CR2 medium on the in vitro production of bovine embryos with cumulus and oviduct coculture. Theriogenology, v.51, n.1, p.259, 1999.

WESTHUSIN, M.E.; LONG, C.R.; SHIN, T. et al. Cloning to reproduce desired genotypes. Theriogenology, v.55, p.35-49, 2001.

YOUNG, L.E.; SINCLAIR, K.D.; WILMUT, I. Large offspring syndrome in cattle and sheep. Reviews of Reproduction, v.3, p.155-163, 1998. 